\title{
Gender, Age, Marital Status, and Education as Predictors to Quality of Life in Elderly: WHOQOL-BREF Indonesian Version
}

\author{
Sharon Gondodiputro, ${ }^{1}$ Aghnia Rizki Hidayati, ${ }^{2}$ Lina Rahmiati ${ }^{1}$ \\ ${ }^{1}$ Department of Public Health, Faculty of Medicine, Universitas Padjadjaran \\ ${ }^{2}$ Diploma IV of Midwifery Program, Faculty of Medicine, Universitas Padjadjaran
}

\begin{abstract}
Objective: To analyze the quality of life in elderly with regards to gender, age, marital status, and education.

Methods: An analytical study involving 88 (eighty eight) elderly who lived in 6 villages in the suburb area of Jatinangor sub-district, West Java, Indonesiawas performed in June 2017. The inclusion criteria were men and women, $\geq 60$ years old, able to communicate in Indonesian, and a mini mental state examination (MMSE) score of $\geq 23$. The variables in the study were gender, age, marital status, and education. Quality of life (QoL) was measured using translated WHOQOL-BREF. Collected data in the study were analyzed statistically using Chi square, Mann-Whitney, Friedman, Post hoc using Wilcoxon, and Kruskal-Wallis tests.
\end{abstract}

Results: The study discovered that all of the respondents had low QoL score $(\leq 60)$. The lowest score was the result of physical domain. There was no significant QoL difference between men and women ( $p>0.05)$ but a significant QoL difference regarding to age, marital status and education level was found

Received:

January 8, 2018

Revised:

February 13, 2018

Accepted:

February 23, 2018 in the study $(\mathrm{p}<0.05)$.

Conclusions: Elderly in suburb area has low QoL and there is a difference in Qol based on age, marital status, and educational level.

Keywords: Education level, elderly, gender, marital status, quality of life

pISSN: 2302-1381; eISSN: 2338-4506; http://doi.org/10.15850/ijihs.v6n1.1201 IJIHS. 2018;6(1):36-41

\section{Introduction}

Indonesia has the $4^{\text {th }}$ largest population in the world after China, India, and United States. In 2050 , around $26 \%$ of Indonesian population, or 72 million citizens, will be over 60 years old with 10 millions will be over 80 years old. ${ }^{1}$ The current health status reports in Indonesia has reflected an apparent shift from communicable diseases to non-communicable or degenerative diseases such as hypertension, stroke, tumor/malignancy, diabetes mellitus, and coronary heart diseases. ${ }^{1}$ This may be worsened by the presence of multimorbidity. There are only a very limited number of studies on multimorbidity in elderly are available in Indonesia. On reviewing data from the 2007

\section{Correspondence:}

Sharon Gondodiputro, Department of Public Healh, Faculty of Medicine, Universitas Padjadjaran

Jl. Dr. Eyckman No. 38, Bandung, Indonesia e-mail: sharon_Gondodiputro@yahoo.com
Indonesian Basic Health Research, Rosyada and Trihandani suggested that the proportion of elderly with diabetes mellitus who also suffered from other diseases was $73.1 \%{ }^{2}$ The impacts of those diseases could influence their quality of life (QoL).

The World Health Organization (WHO) defined the QoL as "individuals' perceptions of their position in life in the context of the culture and value systems in which they live and in relation to their goals, expectations, standards and concerns". ${ }^{3}$ This definition suggested that QoL is an individual subjective evaluation or measurement on his/her life which does not only relate to disease symptoms or diseases but also the impact of those diseases or condition on QoL, both holistically and multidimensially. ${ }^{3}$

Instruments to measure QoL(WHOQOL-100 and WHOQOL-BREF) was developed by the WHOQOL Group in 1995. Skevington et al. ${ }^{4}$ reported that WHOQOL-BREF self-assessment is a sound, cross-culturally valid assessment 
of QoL. In 2004, the WHOQOL BREF had been translated into Indonesian by Ratna Mardiati, Satya Joewana, Hartati Kurniadi, Isfandari, and Riza Sarasvita. Additionally, the questionnaires had been revised twice (in 2014 and 2016) by Fredrick Dermawan Purba. This questionnaire consists of 4 domains: physical, psychologycal, social relationship, and environment domains. The validity and reliability WHOQOl-BREF for Indonesian elderly was tested through a study conducted by Salim et al. ${ }^{5}$ on 306 elderly. The result shows that WHOQOI-BREF is a valid and reliable instrument to measure QoL in elderly.

Quality of life measurement has not been widely performed in Indonesia. Therefore, this study aimed to analyze QoL in elderly based on age, gender, marital status, and education.

\section{Methods}

This was an analytical-comparative study on 88 out of 97 elderly (response rate was $90 \%$ ). The study was conducted in Jatinangor, one of the suburb areas in West Java Province, Indonesia in June 2017. Ethical clearance was obtained from the Health Research Ethics Committee, Faculty of Medicine, Universitas Padjadjaran number 779/UN6.C.10/PN/2017.

Inclusion criteria in this study were elderly people aged $>60$ years old, able to communicate effectively, and not suffering from dementia, which was proven by a mini mental state exam (MMSE) score of $\geq 23$. Exclusion criteria were elderly who was not present during the study.

The sampling method used was multistage random sampling. In this current study, 6 out of 12 villages in Jatinangor subdistrict were selected. The population size off each village varied that a proportional sampling method was applied to obtain a proporsional sample size. After the sample size for each village was determined, simple random sampling was applied to choose one RW (Rukun Warga, a neighborhood unit) from every village. Respondents were then recruited according to the predetermined total sample size using consecutive sampling technique.

Prior to data collection, the objectives of the study were explained to the respondents. If the respondents understood and agreed to participate in the study, the respondents filled out and signed the informed consent provided. Afterwards, the MMSE test was performed and if the score was $\geq 23$, the QoL measurement was then performed by using the Indonesian Version of WHOQOL-BREF. The questionnaire consists of 26 questions:
2 general questions related to respondents' perception on their overall QoL and health and 4 domains with the following details: physical domain with 7 questions, psychologycal domain with 6 questions, social relationship domain with 3 questions, and environment domain with 8 questions. A specific score of 1 to 5 was assigned to each question. After the total score of each domain was obtained, this total score was transformed using a transformation table into a scale of $0-100$. The respondents' characteristics included in the study were age, gender, marital status, and education. The age was divided into two categories, $60-69$ years and $\geq 70$ years. Gender was classified as men and women; marital status was classified into married/still had a spouse and divorced/widower/widow while education was divided into 4 categories: no formal education, primary school graduate, junior school graduate, and senior high school graduate. A study by Silva et al. to assess the diagnostic ability of different cut-off points for the World Health Organization Quality of Life-Bref (WHOQOL-BREF) as a predictor of quality of life in older adult using a ReceiverOperating Characteristic curve (ROC) has discovered a critical value of 60 as the optimal cut-off point for assessing perceived quality of life and satisfaction with health. The area under the curve was 0.758. The QoL level was divided into 2 categories; good QoL with a score of $\geq 60$ and poor QoL scored with a score of $<60 .{ }^{6}$ The collected data underwent a normality test using the Kosmogorov-Smirnov test. The results showed that the data were not normally distributed $(\mathrm{p}<0.05)$. Various statistical analysis were carried out in this study. To analyze the proportion differences of the respondents' characteristics, a chi square test was performed. Other statistical tests performed were unpaired test of 2 groups by using Mann-Whitney test, paired test of more than 2 groups by using Friedman test, Post hoc by using Wilcoxon test, and unpaired test $>2$ groups by using Kruskal-Wallis test.

\section{Results}

The study included 88 respondents with the majority of the respondents were 60-69 years and several respondents aged $\geq 70$ years. The men and women proportion was equal. The results which were based on with or without spouse determined that those who had and did not have a spouse (divorced/widower/ widow) showed the same proportion. Most 
respondents had lower education and only several graduated from high school (Table 1).

This study revealed that most respondents' QoL based on several domains, including the physical, psychologycal, social relationship, and environment domains, seemed to be poor and scored less than 60 (Table 2). Eventhough the QoL of each domain seemed to be equal, a statistical analysis using Friedman test indicated a significantly different score in 3 domains $(\mathrm{p}=0.009)$. To discover which domain had a different score, a Post hoc Wilcoxon test was performed (Table 3). The Wilcoxon test result determined that QoL based on physical domain was lower than the QoL based on the social relationship domain $(\mathrm{p}=0028)$ while the QoL that was based on psychologycal domain was higher when compared to the that of the social relationship domain $(\mathrm{p}=0.001)$. The QoL that was based on social relationship domain was lower when compared to that of the environment domain $(p=0.006)$ (Table 2 and 3).

A significant difference in the respondents' perception on their overall QoL and satisfaction to health based on age, marital status, and educational background was found in this study. The study also found that among the four WHOQOL-BREF domains, the physical domain showed a significant different median score based on education level while psychologycal, social relationship, and environment domains indicated significant differences based on age, marital status, and educational level (Table 4).

\section{Discussion}

This study enrolled 88 elderly who lived in suburb of Bandung, Indonesia as respondents. Data revealed that most respondents had lower education. In general, the QoL in elderly based on all WHOQOL-BREF domains was lower and scored less than 60. The lowest domain score found in the study was physical domain. The result in this study was lower when compared to those of other previous studies by Campos et al. ${ }^{7}$ in Brasil, Bishak et $a l^{8}$ in Iran, and Soósová et al. ${ }^{9}$ in Slovakia. The differences of QoL scores in many countries arose from the facts that aging process is a complex and very individualistic process and influenced by various factors showing relations from one to another. ${ }^{10}$ Economical, cultural, and educational factors as well as health condition can contribute to the QoL. ${ }^{8}$ Another factor which can influence QoL is elderly stereotyping. ${ }^{10}$ According to a study by Diogini ${ }^{10}$, a stereotype can trigger different attitude and behavior among

Table 1 Respondents' Characteristicts Distribution based on Age, Gender, Marital Status, and Education

\begin{tabular}{lccc}
\hline \multicolumn{1}{c}{ Characteristics } & Frequency $(\mathbf{n}=\mathbf{8 8})$ & Percentage (\%) & p Value* \\
\hline Age (yrs.) & & & \\
$60-69$ & 64 & 73 & $<0.001$ \\
$\geq 70$ & 24 & 27 & \\
Gender & 39 & 44 & 0.286 \\
Men & 49 & 556 & \\
Women & & & \\
Marital status & 43 & 49 & 0.831 \\
Divorced/widowed & 45 & 51 & \\
Married/Spouses & & & $<0.001$ \\
Education level & 22 & 25 & \\
$\quad$ No education & 45 & 51 & \\
Primary school & 16 & 18 & \\
Junior school & 5 & 6 & \\
Senior high school & & &
\end{tabular}


Sharon Gondodiputro, Aghnia Rizki Hidayati, et al.

Table 2 Total Score Quality of Life based on Domains

\begin{tabular}{lcccc}
\hline $\begin{array}{c}\text { WHOQOL BREF } \\
\text { Domains }\end{array}$ & Total Score $<$ 606 (\%) & Median/Mean & Minimum & Maximum \\
\hline Physical & 100 & 44 & 19 & 56 \\
Psychologycal & 98.9 & 44 & 25 & 63 \\
Social relationship & 96.6 & 44 & 19 & 75 \\
Environment & 89.8 & 38 & 13 & 69 \\
\hline
\end{tabular}

elderly. Stereotype also determines the way elderly perceives themselves, other elderly (social comparison and thought to grow old), decision-making to join cognitive, social, and physical activities or to look for appropriate medical treatment. A study conducted by Pei et al. ${ }^{11}$ described that participation in social activities become a key to successfully achieve good QoL.

This study discovered that there was no difference in QoL between men and women based on the four QoL domains. Many studies in several countries showed different results. The study conducted by Bishak et al. ${ }^{8}$ in Iran explained the same results as revealed in this study that no QoL difference between men and women. On a contrary, a study conducted by Campos et al. ${ }^{7}$ in Brazil revealed difference QoL was found between men and women. The study also described that there were several factors which can contribute to QoL. In women, the physical health and psychosocial factors contribute to achieving a better QoL while in men, the socioeconomic, physical health, and psychosocial factors can contribute to gain better QoL. ${ }^{7}$ A study conducted by Lokare et al. ${ }^{12}$ stated that difference in QoL between men and women was found in physical and environment domains while in psychological and social relationship domains, no significant difference was identified. A study conducted by Nguyen et al..$^{13}$ has reported that QoL in elderly men was higher than in elderly women based on the four QoL domains.

In terms of the relationship with increase in age, increased age may decrease QoL. This is based on the finding that the QoLscore in elderly aged $\geq 70$ years was lower when compared to elderly whose age were 60-69 years. Aging is regarded as a multidimensional process of physical, psychological and social changes. ${ }^{14}$ Physical changes in aging include decreases in organ functions, progressive changes of body composition, decreases in body lean mass and excess fat, as well as changes in bone density. ${ }^{14}$ Social and psychological factors can contribute to QoL in elderly. Fewer numbers of friends, minimum family encouragements, worthless feeling, lower financial condition, depression, and lonely feeling can cause higher risk to QoL. ${ }^{14}$

With or without spouse condition seemed to have a relationship with QoL. In this study, elderly without spouse presented a lower QoL score when compared to elderly who still had a spouse, particularly based on the of psychology, social relationship, and environment domains. This finding is in line with the results from a

Table 3 Post Hoc Test by Using Wilcoxon Test

\begin{tabular}{lcccc}
\hline \multirow{2}{*}{$\begin{array}{c}\text { WHOQOL BREF } \\
\text { Domains }\end{array}$} & \multicolumn{4}{c}{ Post Hoc Test Results by Using Wilcoxon Test p Value } \\
\cline { 2 - 5 } & Physical Fitness & Psychology & $\begin{array}{c}\text { Social } \\
\text { Relationship }\end{array}$ & Environment \\
\hline Physical & - & 0.266 & 0.028 & 0.319 \\
Psychologycal & 0.266 & - & 0.001 & 0.931 \\
Social relationship & 0.028 & 0.001 & - & 0.006 \\
Environment & 0.319 & 0.931 & 0.006 & - \\
\hline
\end{tabular}


Table 4 Physical, Psychologycal, Social Relationship, and Environment Domains based on Age, Gender, Marital Status, and Education

\begin{tabular}{|c|c|c|c|c|c|c|}
\hline \multirow[b]{2}{*}{ Characteristics } & \multicolumn{4}{|c|}{ Domain WHOQOL BREF (Median Score) } & \multirow[b]{2}{*}{$\begin{array}{c}\text { Social } \\
\text { Relationship }\end{array}$} & \multirow[b]{2}{*}{ Environment } \\
\hline & Q1a & Q2b & Physical & Psychologycal & & \\
\hline \multicolumn{7}{|l|}{ Age (yrs)* } \\
\hline $60-69$ & 4 & 3 & 41 & 44 & 44 & 44 \\
\hline$\geq 70$ & 3 & 2 & 44 & 38 & 25 & 31 \\
\hline $\mathrm{p}$ value & $<0.001$ & $<0.001$ & 0.559 & $<0.001$ & $<0.001$ & $<0.001$ \\
\hline \multicolumn{7}{|l|}{ Gender* } \\
\hline Men & 3 & 3 & 38 & 44 & 44 & 38 \\
\hline Women & 3 & 3 & 44 & 44 & 44 & 38 \\
\hline $\mathrm{p}$ value & 0.554 & 0.847 & 0.171 & 0.124 & 0.668 & 0.959 \\
\hline \multicolumn{7}{|l|}{ Marital status* } \\
\hline Devorced/widowed & 3 & 3 & 44 & 38 & 31 & 38 \\
\hline Married/spouses & 4 & 3 & 38 & 50 & 44 & 44 \\
\hline $\mathrm{p}$-value & 0.001 & $<0.001$ & 0.846 & 0.001 & $<0.001$ & $<0.001$ \\
\hline \multicolumn{7}{|l|}{ Education level** } \\
\hline No education & 3 & 2 & 44 & 38 & 25 & 38 \\
\hline Primary school & 3 & 3 & 38 & 44 & 44 & 38 \\
\hline Junior school & 4 & 3 & 44 & 50 & 50 & 50 \\
\hline Senior high school & 4 & 4 & 38 & 50 & 44 & 56 \\
\hline p-value & $<0.001$ & $<0.001$ & 0.008 & $<0.001$ & $<0.001$ & $<0.001$ \\
\hline
\end{tabular}

Note: Q1a=questions regarding to "How would you rate your quality of life?"

$\mathrm{Q} 2 \mathrm{~b}=$ questions regarding to "How satisfied are you with your health?"

* = statistical test of unpaired 2 groups test by using Mann-Whitney test

$* *=$ statistical test of unpaired $>2$ groups test by using Kruskal-Wallis test

previous study conducted by Sherizadeh et $a l .{ }^{15}$ in Iran. The study explained that married elderly had a maximum score (53.56) when compared to divorced or widowed elderly (43.44). ${ }^{15}$ Marital status significantly relates to mental health. Persons who still have a spouse showed better mental health when compared to those without a spouse. ${ }^{15}$

Repondents in this current study had low education background. Most of the respondents graduated from junior school gaduates, or even lower level. This low educational background influences respondents' perception to QoL. A study by Sherizadeh et al. ${ }^{15}$ discovered similar findings. A positive connection was revealed between literacy and QoL, which may relate to sufficient information received by elderly regarding health and the way to improve QoL. ${ }^{15}$ Respondents with lower education create a limitation in this study due to the possibility that questions were not clearly comprehended by the respondent. Although, this study only analyzed the connection between elderly demography to QoL, the results also contain information which can be used by decision makers in developing distinctive programs for elderly.

It is concluded that QoL in elderly in suburb area is low. Physical domain presented the lowest score when compared to psychologycal, social relationship, and environment domains. No difference in QoL score was found between genders while age, with or without spouse, and education level contribute to QoL. 


\section{References}

1. Cao J, Rammohan A. Social capital and healthy ageing in Indonesia. BMC Public Health. 2016;16(631):1-14.

2. Rosyada A, Trihandini I. Determinan komplikasi kronik diabetes mellitus pada lanjut usia. J Kes Masy Nas. 2013;9(7):395-401.

3. World Health Oranization. WHOQOL-BREF, introduction, administration, scoring and generic version of the assessment. Geneva: WHO; 1996.

4. Skevington SM, Lotfy M, O'Connel KA, The World Health Organization's WHOQOL-BREF quality of life assessment: psychometric properties and results of the international field trialr from the WHOQOL Group. Qual Life Res. 2004;13(2):299-310.

5. Salim OC, Sudharma NI, Kusumaratna RK, Hidayat A. Validitas dan reliabilitas World Health Organization Quality Of Life-BREF untuk mengukur QoL lanjut usia. Universa Medicina. 2007;26(1):27-38.

6. Silva PAB, Soares SM, Santos JFG, Silva LB. Cutoff point for WHOQOL-BREF as a measure of quality of life of older adults. Rev Saúde Pública 2014;48(3):390-7.

7. Campos ACV, Ferreira EF, Vargas AMD, Albala C. Aging, Gender and Quality of Life (AGEQOL) study: factors associated with good quality of life in older Brazilian community-dwelling adults. Health Qual Life Outcomes [serial on the internet]. 2014 Nov [cited 2017 July 20];12(166):[about 11p.]. Available from: https://www.ncbi.nlm.nih.gov/pmc/articles/ PMC4261579/.
8. Bishak YK, Payahoo L, Pourghasem B, Jafarabadi MA. Assessing the quality of life in elderly people and related factors in Tabriz, Iran. J Caring Sci. 2014;3(4):257-63.

9. Soósová MS. Determinants of quality oflife in the elderly. Cent Eur J Nurs Midw. 2016;7(3):48493.

10. Dionigi RA. Stereotypes of aging: their effects on the health of older adults. J Geriatr [serial on the internet]. 2015 Oct [cited 2017 Aug 10];2015(2015):[about 9p.]. Available from: https://www.hindawi.com/journals/ jger/2015/954027/.

11. Pei Y, Gunawan S, Chich-Je S. Correlations between social engagement and quality of life of the elderly in China. Revista Internacional Sociología. 2014;72(Suppl 2):S105-18.

12. Lokare PO, Karanjekar VD, Deotale MK, Jawarkar AK. Assessment of quality of life among elderly population residing at old age homes. Int J Curr Res. 2015;7(4):14552-5.

13. Nguyen TV, Nguyen HV, Nguyen TD, Nguyen TV. Difference in quality of life and associated factors among the elderly in rural Vietnam. J Prev Med Hyg. 2017;58(1):63-71.

14. Amarya S, Singh K, Sabharwal M. Changes during aging and their association with malnutrition. J Clin Gerontol Geriatr. 2015;6(1):78-84.

15. Sherizadeh Y, Sarkhoshi R, Babazadeh T, Moradi F, Shariat F, Mirzaeian K. The quality of life and its related factors in the elderly covered by health care centers in Khoy city, Iran. J Anal Res Clin Med. 2016;4(3):139-45. 